1 Outram D. The body and the French Revolution: sex, class and political culture. New Haven and London: Yale University Press, 1989.

2 Ackernecht EH. Medicine at the Paris Hospital 1794-1848. Baltimore: Johns Hopkins University Press, 1967.

Vess DM. Medical revolution in France, 1789-1796. Gainesville: University Press of Florida, 1975

4 Molière. The complete plays. London: Everyman, 1962

5 Waddington $\mathrm{I}$. The role of the hospital in the development of modern medicine: a sociological analysis. Sociology 1973;7:211-24.

6 Jewson ND. Medical knowledge and the patronage svstem in eighteenth century England. Sociology 1974;8:369-85.

7 Reiser SJ. Medicine and the reign of technology. Cambridge: Cambridge University Press, 1978

Waddington I. The medical profession in the industrial revolution. Dublin: Gill and MacMillan Humanities Press, 1984.

$9 \mathrm{King}$ LS. The medical world of the eighteenth century. Chicago: University of Chicago Press, 1958.

10 Haller $\mathrm{A}$ von. A dissertation on the sensible and irritable parts of animals. (London, J Nourse, 1755), translated from Latin. Bull Hist Med 1936;4: $651-99$

11 King LS. Introduction to Albrecht von Haller. In: Cullen W, ed. First lines of physiologv. Vol 1. New York and London: Johnson Reprint Corporation, 1966.

12 Haigh EL. The roots of the vitalism of Xavier Bichat. Bull Hist Med 1975;49:72-86.

3 Vartanian A, ed. La Mettrie's "l'homme machine": a study in the origins of an idea. New Jersey: Princeton University Press, 1960.

14 Rather LJ. Mind and body in eighteenth-century medicine. A study based on ferome Gaub's De regimine mentis. London: Wellcome Institute, 1965.
15 Temkin O. The philosophical background of Magendie's physiology. Bull His Med 1946;20:10-35.

16 Rosen $G$. The philosophy of ideology and the emergence of modern medicin in France. Bull Hist Med 19+6;20:328-38.

17 Haigh E. Xavier Bichat and the medical theory of the eighteenth century. Medical History 1984; suppl 4

18 Albury WR. French nosologies around 1800 and their relationship with chemistry. In: Forbes EG, ed. Human implications of scientific advance. Edinburgh: Edinburgh University Press, 1978:502.

9 Staum MS. Cabanis: enlightenment and medical philosophy in the French Revolution. New Jersey: Princeton University Press, 1980.

20 Hannaway CC. The Société Royale de Médecine and epidemics in the ancien régime. Bull Hist Med 1972;46:257-73.

21 Peter J-P. Disease and the sick at the end of the eighteenth century. In: Foster $\mathrm{R}, \mathrm{Ranum} \mathrm{O}$, eds. Biology of man in history (selections from the annales). Vol 1. Baltimore and London: Johns Hopkins University Press, 1975.

22 Foucault $M$. The birth of the clinic. Trans by Sheridan AM. London: Tavistock, 1973.

23 Ramsay M. Professional and popular medicine in France 1770-1830. Cambridge: Cambridge University Press, 1988

24 Gelfand T. Professionalizing modern medicine: Paris surgeons and medical science and institutions in the eighteenth century. London: Greenwood Press, 1980.

25 Gillespie CC. Science and polity in France at the end of the old regime. New Jersey: Princeton University Press, 1980:244-56.

26 Thomson JD, Goldin G. The hospital: a social and architectural history. New Haven and London: Yale University Press, 1975.

27 Gelfand T. A confrontation over clinical instruction at the Hôtel-Dieu of Paris during the French Revolution. F Hist Med 1973;28:268-82.

\title{
The GMC perspective
}

\section{Profile of the GMC: portrait or caricature?}

\author{
Robert Kilpatrick
}

(1) The workings of the General Medical Council have been extensively surveyed in these pages over the past nine weeks. Dr Richard Smith's articles have contained a certain amount of basic information about what the GMC does and much conjecture and critical opinion about the way in which it carries out its work. But, surprisingly in a learned journal, he has offered little by way of hard evidence to support the many adverse comments that have been made. The quotations cited have been selective, concentrating on a group of known critics of the GMC with no visible evidence of an attempt to balance their comments with the views, just as sincerely held, of those who think otherwise. In my view these articles have done scant justice to the work of a body which carries out a task which is as vital now as it was when the GMC was first established. I must say that what I have seen of the GMC's work in my 13 years' service bears little resemblance to the body described in Dr Smith's "profile."

(2) In the space available to me it does not seem sensible to attempt to correct every error in the articles or to answer the criticisms one by one. It seems to me that it would be much more profitable-and constructive - to state positively to the profession what are the GMC's priorities for the future.

(3) Before I do that let me simply say, as it would seem from the articles that it needs to be asserted, that the GMC does not seek to stifle innovation in medical education; that it does not discriminate, in any of its procedures, against doctors with "non-European names" or indeed against any group of individuals; and, above all, that it does not act contrary to the wishes of parliament in operating its disciplinary and other procedures.

General Medical Council, London W1N 6AE Robert Kilpatrick, $M D$, president

BrMed f 1989;299:109-12

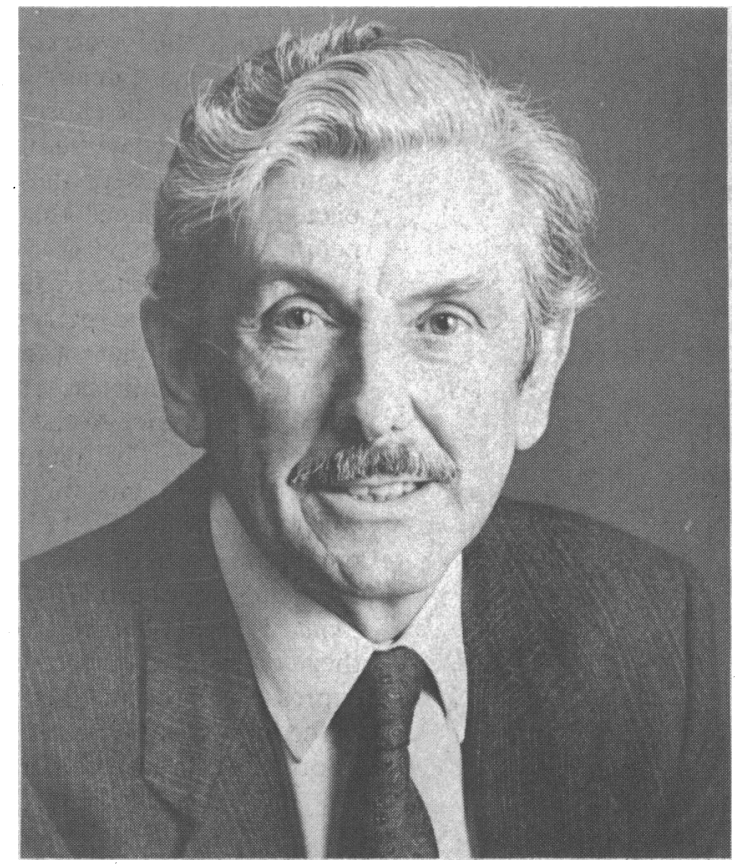

Sir Robert Kilpatrick

of high standards of medical education as a prerequisite for registration; the pursuit of action against doctors whose standards of practice are called into question; and the provision of advice to the profession on standards of professional conduct and medical ethics. All too often I hear the suggestion that the GMC should assume responsibility for this or change its procedures towards that. But any change in the GMC's statutory responsibilities inevitably-and rightly-demands extensive consultation both within and, just as importantly, outside the profession.

(5) When change is needed, and where it is in line with its statutory functions, then the GMC is not averse to change. In the 1970 s it saw the need for a procedure to deal with doctors whose state of health called into question their fitness to practise. It persuaded a 
hesitant profession of the need for this and established a procedure which is generally acknowledged to be working well. It is now considering, as I discuss below, means of assessing 'doctors' performance in order to maintain and promote high standards. On the other hand, it has resisted efforts to turn it into a universal medical complaints agency with which all the public's dissatisfactions with doctors, however minor, may be taken up. That is simply not the function the GMC was set up to perform.

\section{Privilege of self regulation}

(6) It is one of my strongest beliefs that the right which doctors enjoy in this country, of regulating our own profession, is one of the greatest privileges we have. Self regulation, as the Merrison committee said in $1975,{ }^{2}$ is a contract between the public and the profession, enshrining the independence which is essential for any profession's self respect. But, like many important privileges, it is easy to misrepresent as mere self interest; easy to denigrate, but impossible to recover if lost. It goes beyond each individual's regulation of his or her own behaviour, indicating regulation by a whole profession, by a doctor's peers acting corporately. It is a mechanism for promoting standards of practice and professional behaviour which in many ways goes beyond what could reasonably be set down in law. Further, it carries a significant practical advantage: self imposed discipline is much more likely to be accepted by the members of a profession than that imposed from outside. Regulation from elsewhere would, in my view, rapidly reduce our standards to the lowest common denominator.

(7) That is not in any way to suggest that the GMC underestimates the enormous contribution made to its work by the 11 lay members appointed by the Privy Council to represent the public interest. It has long been my experience that the opinions of these lay people are given special weight in the GMC's debates, because they bring to its deliberations a wealth of experience from a perspective which may be quite different from that of many doctors. I have been disappointed, I must say, to see that Dr Smith's articles make no reference to the views of most of the current lay members. The picture given here has been a distorted one, and thoroughly unrepresentative of what I know to be the majority view among those members, seven of whom were moved to write to the press in November 1988 (Sunday Times, 20 November; Sunday Times, Observer, 27 November). In their letter, they commented on recent criticisms of the GMC and expressed the view that "it is our experience that procedures are questioned and reviewed and significant improvements have been and are being implemented."

\section{The GMC in the future}

(8) The principle of self regulation is challenged in certain quarters. It is essential, therefore, that all members of the profession thoroughly understand the central importance of this privilege-enhanced by the presence among our number of distinguished and articulate lay members who participate fully in the work. I cannot believe that any doctor would seriously wish self regulation in this form to disappear, and the GMC will continue to assert and uphold the principle. There are, however, more specific objectives also, chiefly concerning the maintenance and promotion of the highest standards of medical education and practice.

\section{UNDERGRADUATE MEDICAL EDUCATION}

(9) The GMC is rightly seen as the regulator for basic medical education, and during my professional life I have seen the change from the prescriptive stance of the immediate postwar years to the educationally more sophisticated and flexible approach of the past two decades. It has not, however, been as successful as it might have wished in encouraging the medical schools to reduce "congestion and overcrowding in the medical curriculum by instructing less and educating more." ${ }^{3}$ Nevertheless, to suggest that the medical schools have been dilatory in heeding the education committee's recommendations, the most recent of which were issued in 1980 , is to oversimplify the case.

(10) Before the passing of the Medical Act 1978 the law required that at the point of graduation a doctor must possess "the knowledge and skill requisite for the efficient practice of medicine, surgery and midwifery." Although the impossibility of achieving this end, even after exposure to the most congested medical curriculum then available, had long been acknowledged in educational terms, the demands of the act militated against the developments envisaged by the GMC.

(11) Attitudes acquired over a lifetime are slow to change. The more liberal provisions of the 1978 act, which gave to the education committee power to determine "the extent of the knowledge and skill"4 and "the standard of proficiency"s required of the graduating medical student, have to date had a disappointingly modest impact upon the curriculum. It is true that there is a degree of apparent incompatibility between the GMC's philosophy in relation to the curriculum, as stated in the introduction to the 1980 recommendations, and the practical guidance given about the content of the undergraduate course, which may to some extent have obscured our intentions. I am also aware of the enormous pressures on the medical curriculum both from within, in defence of the educational territory allocated to particular subjects or specialties, and from without, by those whose proposals would increase the existing burden of knowledge already borne by our medical students.

(12) It seems to me that pressure is mounting for a further change in the educational climate, to which the GMC may have to respond with a more prescriptive approach in its new recommendations on the undergraduate course, which its education committee has begun to prepare. Not prescriptive in relation to the number of hours of teaching to be allotted to particular subjects or to the order in which the subjects should be taught, but in the sense that the new recommendations will be likely to require of schools a boldness in reviewing their curricula critically while providing the framework within which this should be done.

(13) The GMC is committed to undergraduate teaching of a kind which will produce for the new century doctors whose intellectual and professional development has not been stultified by an onerous burden of knowledge (likely to become rapidly outdated) but who have benefited from a genuinely formative, educational experience. This could be focused on a sound core curriculum supplemented by a sampling of specialist areas of medical practice. We who prepare the new recommendations can only guess at the changes and challenges which those doctors will have to face in the course of their professional lives. We have to ensure that they will have the inquiring minds, the sound scientific base, the essential clinical skills, and the professional attitudes which will enable them to rise to the challenges and assimilate the changes.

(14) I will return below to the scope of these professional attitudes, which include an awareness of the high standards of practice required of every doctor, but I wish to make two points at this stage in response to those who may find the council's approach to undergraduate medical education perplexing.

(15) Medical education should not be regarded as a series of separated compartments. Like all other forms 


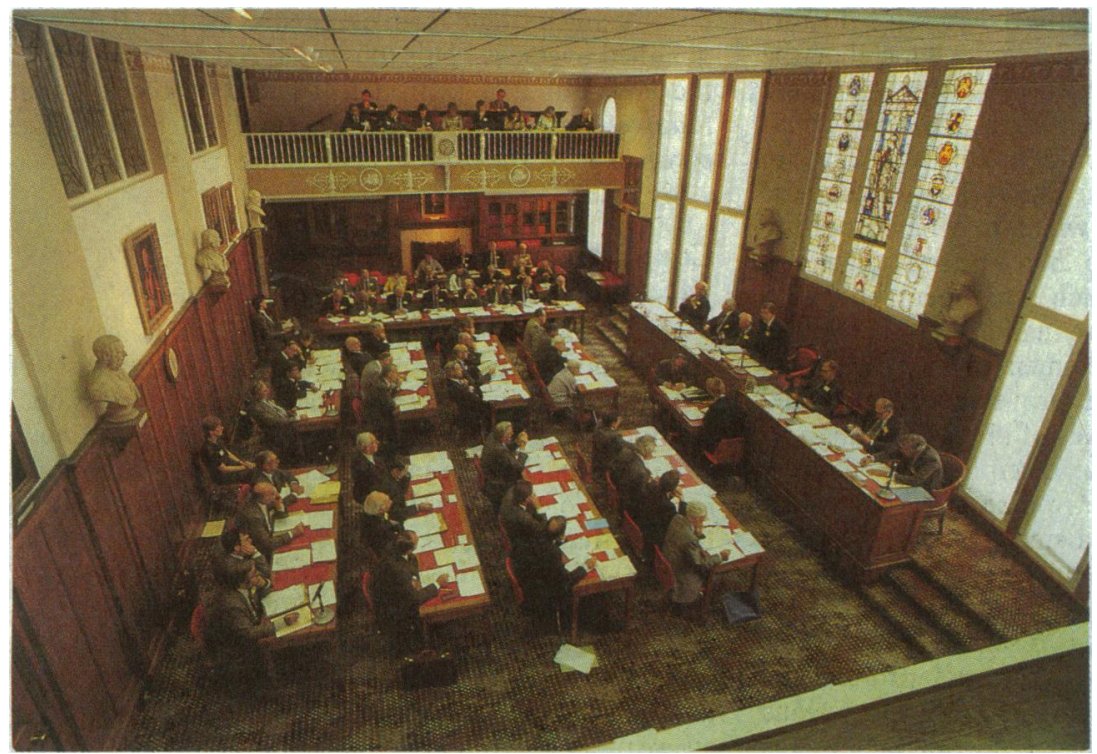

The General Medical Council in session

of education it is a continuum. This is now formally acknowledged in the responsibility given to the education committee for coordinating all stages of medical education. In drawing up new recommendations on the undergraduate medical course the education committee will take as its starting point the fact that for most doctors the completion of basic medical education, during the undergraduate course and general clinical training, is only the first phase in a lifetime of study. Training for independent medical practice, whether in general practice or in one of the hospital specialties, may take on average from four to 10 years after graduation. In revising their curricula medical schools may be reassured that they no longer bear legal responsibility for producing that improbable creature the complete medical practitioner; their graduates must be seen as doctors in the making. From the practical point of view the GMC's commitment to registration of the completion of specialist training, which I discuss below, will ensure that curriculum design need no longer be influenced by the needs of the minority of doctors who have hitherto elected not to participate in postgraduate education and training.

\section{CONTINUING MEDICAL EDUCATION}

(16) The GMC's responsibilities for coordinating medical education obviously extend across the field of postgraduate training, and the recommendations of the education committee have already addressed the questions of general clinical training for the new graduate, and of the training of specialists. The GMC does not, however, regard its responsibilities as having ceased once a doctor secures an appointment as a hospital consultant or principal in general practice and so becomes an independent medical practitioner. It takes great pleasure, as the profession's regulatory body, in acknowledging the high standards of medical practice achieved by the majority of doctors and the enthusiasm with which they seek to further their professional development by participating in the many forms of continuing medical education available nationwide. On the other hand, the GMC does regard it as important for the profession as a whole to guard against complacency, so that it continues to strive constantly for higher standards of patient care, with all that this implies in terms of education and training.

(17) The GMC is also aware that a small proportion of doctors represent a cause for concern in relation to their overall professional performance and is presently considering means whereby the educational needs of these doctors, as well as those of their high achieving colleagues, can best be identified and served. Peer review-the assessment of a doctor's professional performance in terms both of the performance of colleagues in similar circumstances and of accepted standards of good professional practice-is one such means, to which I am personally committed. This differs, of course, both from clinical audit, which measures clinical outcomes against established parameters, and from audit undertaken solely or largely for management purposes.

\section{REGISTER OF POSTGRADUATE TRAINING}

(18) While the development of initiatives such as peer review is ultimately for the benefit of patients, they may also need more direct forms of protection. Patients increasingly seek some tangible means, not simply of distinguishing (as in the last century) the qualified from the unqualified practitioner, but rather of identifying the fully trained doctor who is equipped to treat them or to supervise their treatment. With this in mind the GMC is currently considering, in consultation with the appropriate educational bodies, the feasibility and acceptability of registering the completion of higher specialist training or of establishing a specialist register. We hope that in the foreseeable future it will be possible for the public as well as the profession to use the medical register to distinguish the fully trained practitioner, completion of whose training has been certified to the GMC by the appropriate accrediting or training body.

(19) In educational terms, these are exciting times and when seeking to innovate, as now, the GMC has always drawn extensively on the expertise brought to its work by its own members. Nevertheless, the experience of 90 or so medically qualified GMC members is not a substitute for the widest possible consultation on any proposals that it may have for educational innovation. The GMC does not regard the consultation process simply as a mirror in which it will expect to see its own face reflected. I acknowledge here the great debt which it owes to the royal colleges as well as to the many other bodies involved, directly and indirectly, in undergraduate and postgraduate education and training. I like to think that this fruitful cooperation arises out of our mutual commitment to the advancement of medical education and training and to the well being of future generations of doctors and patients.

\section{ASSESSMENT OF PERFORMANCE}

(20) The education committee is working on means whereby doctors' educational needs, in postgraduate and continuing medical education, can be identified and served. But, as I said above, a small number of doctors may not be achieving the standards of performance of which they should be capable. Much publicity has recently been given to the GMC's proposal to introduce a third procedure, separate from the disciplinary and health procedures. It has been somewhat imprecisely referred to as a "competence procedure," but I should prefer to talk about a doctor's performance rather than competence. Competence can mean too many different things to different people.

(21) Amendment of the medical act would be needed before the GMC could take on any new function in relation to the assessment of doctors' performance. This must be preceded by widespread discussion with the profession, because bodies like the royal colleges have already developed important roles in this area. The initiative being taken by the GMC is intended to complement rather than supercede the work which is already going on. There must be discussion with other bodies too, because the GMC's consideration of the problem would include evaluation of the arrangements for audit within the NHS 
(although it will also look at the position of doctors not practising in the NHS). I would hope that the proposals will be based on the principles of peer review, handled in the main by local rather than central arrangements. The aim should be, in my view, to review a doctor's performance rather than to judge the outcomes of particular cases which may be brought to the GMC's attention. I do not underestimate the difficulties of establishing such assessment but, with the profession's help, I believe that it can be achieved.

(22) I also believe that assessment of performance, if properly implemented, will improve upon, and indeed make redundant, the proposals of Nigel Spearing MP for additional procedures for disciplining doctors. I appreciate the sincerity of $\mathrm{Mr}$ Spearing's views, which are based on his opinion of a single case heard seven years ago-it is in fact the only case quoted in Dr Smith's articles-but Mr Spearing appears to wish the council to hold public disciplinary hearings of complaints, not just about serious professional misconduct but also about demonstrably less serious aspects of a doctor's conduct. I do not believe, as I have already said, that the GMC can become a general complaints agency for matters of this kind. Other "agencies" must be brought into play: the medical schools and postgraduate training bodies in "preventive" and educational roles, local mechanisms for peer review, and existing local complaints procedures.

(23) As in its current disciplinary procedures, so in assessment of performance in the future, I should expect the GMC to become concerned only in the cases of doctors who have failed, or proved unable, to maintain the standards of their peers to a degree which calls into question their registration.

\section{REGISTRATION FOR DOCTORS QUALIFIED OVERSEAS}

(24) Criticism has been levelled at the arrangements in the medical act for the registration of doctors qualified overseas (that is, those who have qualified outside the European Community). These distinguish between those primary qualifications awarded overseas that are recognised for the purposes of granting full registration and those that are not, but that may be accepted for limited registration. There is no denying that the arrangements for teaching undergraduate medical students overseas vary considerably. But a new element was introduced when the government imposed a four year restriction on the period for which any overseas doctor, regardless of registration status, may engage in postgraduate training here without a work permit. The GMC is exploring the possibility of introducing a single form of registration for all doctors qualified overseas. This too would require a change in the law, but if it proved to be practicable it might remove some of the problems which stem from the complexity of the present arrangements.

\section{Conclusion: medical standards and the uncertainties of the future}

(25) I have referred a great deal in this article to standards. I make no apology for that. Standards-of medical education, medical practice, and professional conduct-are what we are about. Doctors enjoy a privileged position in society and must therefore accept regulation of their activities on behalf of society. It can be said that the GMC stands as a bridge between the public and the profession, and like any bridge must endure a certain amount of trampling. Some criticism from both sides is inevitable for any such regulatory body. But this does not mean that we are necessarily getting the balance wrong. While the GMC is acutely aware of its disciplinary responsibilities, it is not just a complaints agency. Its task goes above and beyond this. I see that task not as the defence of an established position, against whatever criticism, but as a means whereby the aspirations and ideals of the medical profession may be expressed and upheld. I believe that the majority of the GMC's lay members take the same view.

(26) The medical profession faces many uncertainties at the present time. The danger of a growth of defensive medicine, increasing pressures towards competition and even a degree of commercialisation, and the questioning of the validity of self regulation all pose problems, challenges, and opportunities in about equal measure. Similarly, our patients face uncertainties about the future arrangements for providing medical services on which they have hitherto relied. What will ultimately be of greatest benefit to our patients - and will give to the profession the best hope of stability and a sense of direction as circumstances change - is the maintenance by doctors of the highest standards of medical practice. The GMC sees this as its first priority, and I am confident that it will continue to enjoy the support of the profession in achieving it.

1 Medical Act since 1858 and subsequent acts.

2 Committee of Inquiry into the Regulation of the Medical Profession. Report. London: HMSO, 1975. (Cmnd 6018.) (Merrison report.)

3 General Medical Council. Recommendations on basic medical education. London: GMC, 1980. (Paragraph 10.)
General

4 Medical Act 1956. London: HMSO, 1956. (Section 10(1).)

5 Medical Act 1983. London: HMSO, 1983. (Section 5; originally section 15, Medical Act 1978.)

\section{ANY QUESTIONS}

The sedative effects of psychotropic drugs would be expected to wear off after a few weeks, but a young patient taking $25 \mathrm{mg}$ amitriptyline three times a day and zuclopenthixol $200 \mathrm{mg}$ fortnightly for four months finds it hard to get up in the morning. What might be the cause of this prolonged sedation?

The drugs used, amitriptyline and zuclopenthixol, are two of the most sedative drugs used in psychiatry. The antidepressant most similar to amitriptyline, but without its sedative properties, is probably imipramine. If the patient remains oversedated despite changing to this then the use of a secondary amine, such as nortriptyline or protriptyline, might be even more satisfactory, although these drugs suffer from the hypothetica drawback of a possible therapeutic window in prescribing. Zuclopenthixol is a long acting depot injection of the thioxanthene group of drugs, and the nearest drug in action without its sedative action would be flupenthixol ( $40 \mathrm{mg}$ fortnightly would be the equivalent).

Why is the patient taking this particular combination, and could the antidepressant be discontinued? The issue of prescribing antidepressants to schizophrenic patients is complex and has not been fully resolved. So far there have been only two double blind trials testing the efficiency of antidepressants in treating new depressive symptoms in patients taking regular maintenance treatment. One study gave a positive result in postpsychotic depression ${ }^{1}$ and another gave a negative result in patients who had been stable for more than 12 months living in the community. ${ }^{2} \mathrm{~A}$ third study, evaluating the combination of a tricyclic antidepressant and a neuroleptic given in combination over four months, showed no overall advantage at the end of that time and many patients failed to complete the study because of a deterioration in the incidence of thought disorder. ${ }^{3} \mathrm{At}$ present tricyclic antidepressants should be prescribed only to patients with chronic schizophrenia receiving maintenance treatment on the basis of therapeutic trial. The difficulty in getting up in the morning might be part of the loss of volition in a chronic schizophrenic state rather than the direct sedative effects of the drugs prescribed.-D A W JOHNSON, consultant psychiatrist, Manchester

1 Siris SG, Dan F, Cohen M, Mandeli J, Aronson A, Fasano-Dube B. Targeted treatment of depression like symptoms in schizophrenia. Psychopharmacol Bull 1987;23:85-9.

2 Johnson DAW. Studies of depressive symptoms in schizophrenia. Br $\mathcal{f}$ Psychiatry 1981;139. 89-101.

3 Prusoff BA, Williams DH, Weissman MM. Treatment of secondary depression in schizophrenia. Arch Gen Psychiatry 1979;36:569-75. 